\title{
Wenceslau de Moraes, suas obras e o serviço exterior português na Ásia ${ }^{1}$
}

\section{Sérgio Pereira ANTUNES ${ }^{2}$}

Wenceslau de Moraes, um dos poucos escritores do universo da língua portuguesa que conseguiu se despir de preconceitos de branquidade e viveu intensamente o mundo oriental, coloca-se ao lado de grandes personalidades universais a exemplo do francês Paul Gauguin e do norte-americano Lafcadia Hearn (FonsECA, 2003, p. 9).

Wenceslau de Moraes é fruto de um contexto marcado por importantes mudanças da história universal e, por consequência, traz sua vida imbuída de transformações observadas, anotadas e criativamente narradas em suas obras, refletindo a

1 Versão deste texto foi publicada na Revista de Cultura, Macau, n. 49, p.35-43, 2015. Edição Internacional.

2 Graduando em Economia pela Pontifícia Universidade Católica de São Paulo e em Direito e Letras pela Universidade de São Paulo. Mestre em Integração da América Latina, Doutor em História Econômica e Pós-doutorado em Direito Constitucional Comparado e em Cultura Chinesa, pela Universidade de São Paulo. Membro do Grupo de Pesquisa Pt Oriente e do Laboratório de Interlocuções com a Ásia (LIA); santunes@usp.br 
compreensão do universo oriental que quis voluntária e profundamente conhecer.

Foi também por meio das observações narradas por Wenceslau, com exímia beleza literária, que o mundo ocidental, em especial o de língua portuguesa, foi brindado com importantes obras que revelam o Oriente por um testemunho ocular. Delas vale lembrar: Traços do Extremo Oriente (1895) - obra que apresenta as primeiras sensações em terras de exótica beleza por toda Ásia, destacando Macau, China e Japão; Paisagens da China e do Japão (1906) - obra mais madura explorando e revelando ao ocidente contos, lendas e fábulas imemoriais do Oriente; Dai Nippon (1897), talvez a mais completa obra a tratar do mundo nipônico; entre outras tantas obras dedicadas à cultura do extremo oriente.

Pelas observações traçadas por Wenceslau de Moraes, em suas obras, podemos compreender a dedicação do oficial da marinha portuguesa no cumprimento de importantes missões e inestimável apoio para as políticas externas do governo português.

Assim, para a adequada compreensão da importância de Wenceslau de Moraes no quadro proposto, parece-nos recomendável averiguar o contexto histórico de sua época; traçar, brevemente, aspectos de sua vida e de sua carreira; delinear características essenciais de algumas obras; e, por fim, analisar o conteúdo de cariz diplomático com que Wenceslau brindava seus leitores, descortinando o mundo oriental daquela época.

\section{Contexto histórico}

O século XIX assistiu a uma inédita evolução da sociedade em diferentes campos, desde o tecnológico, o social, até o econômico, que mudou o rumo da própria história mundial. 
No contexto mundial, a história revela o espraiamento da Revolução Industrial iniciada na Inglaterra no século XVIII, bem como o seu reflexo no ordenamento econômico internacional. A industrialização da Inglaterra e de outras nações criou um excedente de produção que, em princípio, não encontrou a prontidão de um mercado consumidor. Assim, o enriquecimento e o poder econômico dessas nações dependiam da criação de um mercado favorável, que só pôde ser construído com a imposição de tratados desiguais, nos moldes do pioneiro tratado de abertura dos portos brasileiros às nações amigas, ou seja, o Tratado de Amizade e Comércio.

As rotas comerciais também se alteraram. Desde a inauguração e abertura à navegação internacional do Canal de Suez, não era mais necessário contornar a África para a Europa alcançar o Extremo Oriente. Da mesma forma, a evolução tecnológica aparelhou as embarcações com equipamentos mais precisos de navegação além de torná-las mais seguras. As naus de madeira com mastros e velas foram substituídas por embarcações com casco de metal e motores propulsores. Novas atividades econômicas emergiram: surgiram o turismo e o interesse por conhecer novos lugares, em especial aqueles exóticos, que passam a ser muito explorados pela literatura especializada a exemplo das narrativas de viagem. Surgiram, então, as companhias de turismo, os hotéis de luxo e todo o aparato de apoio necessário a essa atividade. No final do século XIX, o turismo contava já com o poder de uma máquina maravilhosa: a câmara fotográfica. A dependência pelos produtos orientais, em especial os artesanais, passou a ser relativizada ante a possibilidade de substituição pelos produtos criados pela Revolução Industrial.

Portugal também assistiu, nesse período, a uma série de mudanças. No início do século XIX, as guerras napoleônicas 
levaram a sede da metrópole portuguesa para terras brasileiras. Mais tarde, em 1822, com a independência do Brasil, Portugal perdeu uma importante parcela de sua economia. Restou, então, transformar suas demais colônias em um "grande Brasill". Para novos processos de exploração e de atendimento do interesse econômico, novas políticas foram lançadas em face de Angola, Moçambique, outros pequenos territórios na África (Cabo Verde, São Tomé e Príncipe, Guiné Bissau), os territórios coloniais na Índia (Goa, Damão e Diu, já que havia negociado e cedido Bombaim para a Inglaterra), e os longínquos territórios de Macau e Timor.

A China, por sua vez, até 1840, dominava a ordem econômica mundial como o grande fornecedor da economia global e hegemonia em toda a Ásia. Entretanto, a partir da I Guerra do Ópio, perpetrada pela Inglaterra, cujo desfecho se deu com a assinatura de um tratado desigual (Tratado de Amizade e Comércio), impondo à China a cessão da ilha de Hong Kong e a possibilidade de estabelecimento comercial inglês em território chinês sob jurisdição britânica, além do livre comércio de benefício unilateral. Tais medidas acabaram por levar a China a uma estagnação econômica inédita e uma severa crise social nunca antes vistas. Outras potências imperialistas (Estados Unidos da América, Países Baixos, França, etc.) seguiram e se aproveitaram dos passos britânicos em face à China, piorando sua situação econômica e social. Se, no começo do século XIX, a China tinha a hegemonia econômica no Oriente, ao final desse mesmo século, restou-lhe assistir ao crescimento dos imperialistas, incluindo o Japão, com pretensões hegemônicas na região.

Nesse contexto, a autonomia de Macau perante a China torna o território uma verdadeira colônia portuguesa. Fato que impingiu a Portugal o incremento de sua presença, tendo, a partir da assinatura do Tratado de Amizade e Comércio Sino-portu- 
guês, de administrar o território e toda a sua gente, não só os portugueses e estrangeiros, mas também os chineses. É desse período a introdução de escolas luso-chinesas. Além disso, a língua portuguesa passou a ser ensinada aos chineses, o território ganhou seu primeiro instituto de ensino médio, o Liceu de Macau, e fluíram para Macau altos funcionários da coroa portuguesa: juízes, agentes aduaneiros, professores, imprensa, etc. Assim, embora Macau tenha que compartilhar sua hegemonia do comércio sino-internacional com Hong Kong, acaba recebendo atenção de Portugal.

\section{Aspectos da vida e da carreira de Wenceslau de Moraes: Marinha e Macau}

Wenceslau de Moraes, nascido em 1854, assistiu a essa transformação histórica. Ingressou na Escola Naval em 1872 e logo se engajou na Marinha Portuguesa, que também assistia à evolução tecnológica daquele século. Tanto que Wenceslau iniciou, em 1874, sua carreira, embarcado na Corveta Bartolomeu Dias - uma embarcação simplória de casco de madeira e ainda movido pela força do vento. No correr dos anos, assumiu postos embarcado em navios cada vez mais evoluídos, chegando a Macau servindo como oficial na Canhoneira Rio Lima, uma embarcação encouraçada e moderna.

Nem só de tecnologia evoluía a Marinha, eis que, com a independência do Brasil e a necessidade de Portugal fazer de suas demais colônias um grande Brasil, conforme vimos, a Marinha Portuguesa foi incumbida de nova missão, tornando-se o abraço executivo das relações exteriores e da diplomacia portuguesa.

Assim, a Marinha marca a formação e a vida de Wenceslau de Moraes, que faz uma carreira de marítimo, mas também de diplomata. 
Macau igualmente marcou a formação, a vida e, sem dúvida, o ponto de partida para o processo de orientalização de Wenceslau de Moraes. Foi em Macau que, pela primeira vez em sua carreira na Marinha Portuguesa, assumiu um cargo em terra firme. Foi, por consequência, em Macau que fixou residência, montou seu lar, casou, teve seus dois filhos, lecionou, participou ativamente da vida social do lugar, fez várias viagens ao Japão, apaixonando-se pela cultura nipônica, escreveu e de lá fez publicar seus dois primeiros livros Traços do Extremo Oriente e Dai Nippon.

Foi também em Macau, que Wenceslau se decepcionou com a Marinha. Por se sentir preterido na nomeação do Superintendente do Porto, pediu exoneração e decidiu a grande guinada de sua vida, abandonando tudo e seguindo só para o Japão com intento claramente de orientalização.

\section{Entre as obras de Wenceslau de Moraes, algumas características}

Wenceslau de Moraes escreveu grande gama de obras literárias que revela as complexas relações internacionais de sua época. Nesse complexo contexto, o autor trata do universo chinês, destacada e expressamente, em duas de suas obras: Traços do Extremo Oriente e Paisagens da China e do Japão.

É na obra Traços do Extremo Oriente que os primeiros contatos orientais são reportados e há, portanto, importantes informações sobre a Tailândia, Singapura e Indonésia. Todas essas paragens são cenários de seus contos e de suas narrativas de viagem. O Japão predomina a maior parte de sua obra, que é composta de várias publicações de peso, além de Traços do Extremo Oriente, de 1895, e Paisagens da China e do Japão, de 1906; Dai Nippon, 
em 1897; Cartas do Japão, em 1904; O culto do chá, em 1905; O Bom-Odori de Tokushima, em 1916; O-Yone e Ko-Haru, em 1923; Fernão Mendes Pinto no Japão, em 1920; Relance da História do Japão, em 1924; Os Serões no Japão e Relance da Alma Japonesa, ambas em 1926.

Traços do Extremo Oriente, o primeiro livro de Wenceslau de Moraes, que veio a ser publicado em Lisboa em 1895, apresenta características peculiares. Escrito aos moldes das narrativas de viagem, descrevendo rotas, lugares e paisagens, tem o narrador presente e que, com alguma cerimônia, dialoga com o leitor. A referida obra é composta por uma carta dirigida a sua irmã e por vários contos escritos e recolhidos pelo autor desde 1885. Além de um post scriptum e um conto tratando de Batávia, a capital holandesa da ilha de Java (hoje Jacarta). A obra está dividida em três partes: as "Recordações do Sião", "Lembranças da China" e "Saudades do Japão". Por esses subtítulos, já se percebe sua predileção peloJapão, uma vez que dali tem saudades, da China, só lembranças e da Tailândia, recordações.

A obra Paisagens da China e do Japão, publicada em 1906, também tem suas peculiaridades. O teor da escrita revela um amadurecimento acerca do conhecimento daquelas paragens orientais. No contexto das obras produzidas para leitores ocidentais de língua portuguesa, seu teor é de extrema importância, eis que traz à luz do universo lusófono contos e lendas do mundo chinês e japonês, sendo que muitos deles, até hoje, são obras únicas a respeito desse imaginário literário oriental. A obra congrega 17 contos, tratando especificamente da China e do Japão, sendo que, em três deles, o ambiente do enredo é Macau: a) "O ano novo"; b) "Pau-Man-Chen"; e c) "Amores".

Em ambas as obras aqui tratadas (Traços do Extremo Oriente e Paisagens da China e do Japão), podemos observar que: a) o ambiente é oriental (Tailândia, Indonésia, Singapura, Macau, 
Hong Kong, China, Japão); b) os personagens se assemelham são chineses ou japoneses (orientais no geral), europeus, e elementos culturais que acabam sendo tratados como personagens; c) há qualificações pejorativas, quase sempre vinculadas à China, e qualificações próprias de exaltação, quando trata de Macau e Japão.

A respeito das menções feitas a Macau, em Traços do Extremo Oriente, encontramos adjetivações interessantes: "pequenino", "dia belo, montanhas doiradas pelo Sol", "boa gente chinesa", "existência fácil, clima salubre", "viver modesto... ingênuo e bom", "encosta coberta de relva, um veio de águas límpidas". Em Paisagens da China e do Japão, Macau é igualmente bem referido: "um canto exótico, longe muito longe do torrão em que nasceu”, “... a brandura dos costumes".

Em ambas as obras, Macau aparece como um longínquo território português na Ásia: "Portas do Cerco, limite de nosso domínio colonial", "Pequenino Macau português", "Macau, onde, pela primeira vez, a raça branca implantou poderes no império" (Moraes, 2012), e "Aqui no fim do mundo, no seio desta colônia nostálgica", "exíguo penedo asiático, onde Portugal implantou a sua bandeira" (Moraes, 2007).

Macau, entretanto, na obra Traços do Extremo Oriente, é também referido como um território chinês: "esse pobre torrão chinês onde me encontro". O mesmo não acontece em Paisagens da China e do Japão, onde apenas referência a Macau portuguesa foi localizada.

\section{Conteúdo diplomático na obra de Wenceslau: serviço exterior português}

Como já dissemos, Wenceslau de Moraes é produto do contesto histórico de sua época. Logo cedo em sua carreira de 
oficial da Marinha, abraçou e desempenhou a missão atribuída àquela força armada de ser o braço executivo das políticas externas portuguesas, lidando em suas funções com a plena realização do serviço exterior português.

No desempenho dessas funções, vale lembrar suas primeiras ações, à semelhança dos atos próprios do serviço exterior, embora não fosse à época funcionário diplomático ou mesmo de generalidade das funções dos negócios estrangeiros. Assim, participou da celebração do Tratado de Amizade com o Sultão de Zanzibar, em 1883.

A respeito, é interessante comentar que os tratados da espécie eram extremamente comuns à época e tiveram origem no molde daquele que pioneiramente foi assinado entre Portugal e Inglaterra, abrindo os portos do Brasil às nações amigas. Esses Tratados de Amizade e Comércio constituíram, na verdade, os expedientes que ficaram conhecidos como tratados desiguais, por não conter equidade no tratamento das partes, criando verdadeiros tratos de exclusividade e benesse para apenas um dos lados. No caso brasileiro, a abertura dos portos às nações amigas, em princípio, teve única e exclusivamente a Inglaterra como beneficiária.

Esses tratados se espalharam pelo mundo criando os privilégios dos europeus e americanos na construção da hegemonia mundial, consolidando o imperialismo em detrimento das demais partes, que ficaram reduzidas a uma segunda categoria de nações.

Como homem de seu tempo, Wenceslau, por seu tino diplomático e humanista, identifica muito bem a problemática desse período, o abuso europeu baseado nos canhões ou nos tratados da espécie. Consciência que revela com clareza em Paisagens da China e do Japão: 
[...] período de frenesi da Europa, de curiosidade, de cobiça, em face da morna inércia deste canto do mundo; e as esquadras que o devassam, que o visam com os canhões; e os diplomatas que intrigam, que teimam, conduzindo-o finalmente, à força, ao convívio das nações. (MORAEs, 2007, p. 101)

Igualmente, Wenceslau de Moraes atuou na representação de Portugal em sua visita ao Reino do Sião (atual Tailândia), como ficou muito bem registrada no conto "Em Bangkok" (Banguecoque), no capítulo "Recordações do Sião" de sua obra Traços do Extremo Oriente. Ali Wenceslau reporta essa visita em detalhes ao ser recebido por amável príncipe, já que Sua Majestade Somdetch P'ra Paramindr Mahah Chulalongkorn estava ausente, e ilustra, ainda, seu olhar europeu sobre os costumes exóticos, relatando o ataque de um felino de estimação no Palácio Real.

Uma curiosidade a observar é um soberbo leopardo, solto, livre, passeando ao seu sabor, aproximando-se de nós, fixando-nos por vezes as suas pupilas nostálgicas. _ "Manso como um gatinho" - é a frase de sua alteza. No entanto o dulcíssimo animal encara de quando em quando, carrancudo, os grupos de escravos quase nus, que enxameiam nos vestíbulos. Provoca risos o seu mau humor. Uma mulher, por brincadeira empurra para frente um rapaz que está próximo. O rapaz solta uma gargalhada. O leopardo, ao que parece, não gosta de gargalhadas; dá dois pulos, chameja-lhe o olhar. $\mathrm{O}$ rapaz foge, a rir-se ainda; e o leopardo avança em ondulações, sem ruído, com patas de veludo; envolve-se 
com ele, abraça-o, rasga-lhe as carnes, deixa-o morto. (Moraes, 2012, p. 11)

É também em Traços do Extremo Oriente que Wenceslau nos reporta muito sobre o Japão, cumprindo missões governamentais: em 1889, a primeira de importância; em 1892, quando foi ao Japão para aquisição de defesa para Macau; depois, em 1894 e em 1897, quando, na companhia do Governador de Macau, foi recebido pelo Imperador do Japão, momento raro da diplomacia portuguesa.

A título ilustrativo, basta lembrar a descrição feita por Wenceslau sobre Yokohama, demonstrando a forte presença estrangeira e consignando a ausência do outrora pujante comércio português que, no século XVI, havia inaugurado essa atividade internacional por aquelas terras nipônicas:

Ingleses, americanos, franceses, chineses, judeus, vendilhões de todo o mundo, invadiram há já longos anos o país, e aqui assentaram de preferência arraiais, para estendal dos seus produtos e colheita dos alheios; abrindo ruas, erguendo edifícios - habitações, armazéns, fábricas, - com a feição cosmopolita duma babel qualquer comercial. Aqui é um hotel, ali um clube, além um campo do tennis ou uma igreja protestante; e casinhas entre jardins, garridas, no gosto britânico. Mas nada disto é japonês; nem quase japonês é este povo, descaracterizado pelo contato com estranhos... (Moraes, 2012, p. 166)

Essa abertura comercial e a presença marcante do mundo ocidental em Yokohama são explicadas por Wenceslau, em 
Paisagens da China e do Japão, onde resta bem claro que tal poderio estrangeiro em terras do Oriente, mais uma vez, só foi conseguido por tratados desiguais, ou seja, pelos Tratados de Amizade e Comércio celebrados:

O shogun, generalíssimo do imperador, com residência em Yedo, assinara por conta própria tratados de amizade e de comércio com a América e com a Europa, e os estrangeiros, em Yokohama, pisavam já afoitamente o solo japonês. (MoRAEs, p. 114)

\section{É em Traços do Extremo Oriente que Wenceslau representa e apresenta seu país ao Oriente:}

[...] pergunta-me se o meu país é um poderosíssimo estado. Digo-lhe que não, o que ele bem sabe; e acrescento que já o fora.

- Sim, - acode-me o garoto com ares de profeta, - é a sorte das nações. Portugal já foi o primeiro país do mundo; hoje é a Inglaterra; amanhã será a Rússia; depois de amanhã será o Japão. (Moraes, 2012, p. 259)

Talvez o mais importante a se destacar nos escritos de Wenceslau é sua diplomacia humanitária, quando, por exemplo, dá a receita para os imperialistas alcançarem admiração por uma vertente mais humana:

[...] ódio intransigente que todo o chinês vota aos europeus...

Foi nesse meio tão insólito, que eu... me entretive a fazer brotar simpatias... Sorria-me para os bebés; afagava... 
suas mãozinhas papudas; mostrava por qualquer forma que eles me interessavam. A boca, que ia vomitar uma obscenidade, calava-se; a expressão canalha dum olhar tornava-se meiga, transluzia um agradecimento no fogo da pupila. E era tão franco o rosto que me acolhia, tão limpo de maldade, que eu iria confiante... (MORAES, 2012, p. 63-64)

Traços do Extremo Oriente é ainda importante documento histórico, eis que Wenceslau fez ali incluir a tradução da declaração da Guerra Sino Japonesa. Trata-se de um panfleto em que o Imperador do Japão conclama seus súditos a promover a guerra contra a China. E as razões? Ora às razões! Para guerra não há arrazoado plausível; assim foi também no conflito armando do Japão contra a China: não há razões ou melhor, como aquelas declaradas pelo Imperador japonês só se pode concluir a mera vontade bélica promovida pela corrida armamentista típica do período

Nós, pela graça do céu, Imperador do Japão, assentado no mesmo trono ocupado pela nossa dinastia desde tempos imemoriais, proclamamos o seguinte aos Nossos leais e bravos súditos.

Declaramos, por este, guerra contra a China, e ordenamos a cada uma e a todas as autoridades competentes, em obediência aos Nossos desejos e a fins de glória da nação, que fomentem por mar e por terra a guerra contra a China, com todos os meios ao seu dispor, conformemente as leis das nações.

Durante as passadas três décadas do Nosso reinado, o que temos sempre almejado, é o progresso pacífico 
do país por meio da civilização, e sendo sensível aos males que sempre acompanham as complicações com as potências estrangeiras, sempre foi de o nosso agrado dar instruções aos Nossos ministros de Estado a respeito das relações amigáveis com as Nossas potências dos tratados. Congratulamo-nos por saber que as relações do Nosso império com estas potências aumentaram sempre satisfatória e amigavelmente. Por aquelas circunstâncias, não estávamos preparados para uma tão evidente falta de amizade e boa fé, como há pouco manifestou a China, na sua conduta para com este país, concernente à questão coreana.

A Coreia é um estado independente. Mereceu ela entrar no grêmio das nações, aconselhada e guiada pelo Japão. Foi, contudo, costume da China designar a Coreia como dependência sua, e os impérios japonês e chinês interferiram nos seus negócios, tanto aberta como secretamente. Por ocasião da última rebelião civil da Coreia, a China enviou para ali tropas, alegando ser propósito seu defender um estado seu dependente. Nós, em virtude do tratado concluído com a Coreia cm 1882, e olhando a acontecimentos futuros, ordenamos também que se enviasse para aquele país uma força militar. Desejando procurar que a Coreia esteja para sempre isenta de perpétuos distúrbios, e por isso manter também a paz do Oriente em geral, o Japão convidou a China a cooperar com ele para a realização deste fim. A China, porém, alegando vários pretextos, recusou o convite do Japão. Depois disso o Japão aconselhou a Coreia a que reformasse a sua administração, de maneira a manter-se no país a ordem e a tranquilidade, podendo assim este 
reino desempenhar-se dos deveres e responsabilidades dum estado independente perante o estrangeiro. A Coreia consentiu neste Nosso desejo. Porém a China secreta e insidiosamente tem diligenciado iludir e estorvar os planos do Japão. Além disso tem procrastinado e procurado fazer preparativos bélicos tanto por mar como por terra. Depois de estes preparativos estarem prontos, não só enviou grandes reforços à Coreia a fim de forçosamente conseguir os seus desígnios ambiciosos, mas levou ainda a arbitrariedade e insolência a fazer fogo sobre os Nossos navios nas águas coreanas. O plano da China é tornar duvidoso onde reside a responsabilidade de preservar a paz e a ordem na Coreia, e não só enfraquecer a posição deste país no grêmio das nações - posição obtida para a Coreia pelos esforços do Japão - mas também obscurecer a importância dos tratados, reconhecendo e confirmando essa posição. Tal conduta por parte da China é não somente uma injúria direta aos direitos e interesses deste império, mas também uma ameaça à paz permanente e à tranquilidade do Oriente. Julgando pelas suas ações, deve concluir-se que a China, desde o princípio, se inclinou a sacrificar a paz para atingir os seus sinistros fins. Nesta situação, como é Nosso ardente desejo promover o prestígio do país no estrangeiro por métodos restritamente pacíficos, achamos impossível evitar uma formal declaração de guerra contra a China. É nosso ardente desejo que, pela lealdade e valor de Nossos bravos súditos, em breve se estabeleça a paz permanente, e que a glória do Império aumente e se complete. Dado no $1^{\circ}$. dia da oitava lua do ano $27^{\circ}$ de Meiji. (MORaes, 2012, p. 253-255) 
O cargo próprio de Wenceslau de Moraes no serviço exterior português só viria muitos anos mais tarde, em 1899, quando, por intervenção de Vicente d'Eça, seu editor e amigo, assumiu os serviços nos consulados de Kobe e Osaka, onde, em 1913, se tornaria Cônsul Geral.

Um pouco antes de sua nomeação oficial no serviço exterior, Wenceslau de Moraes atuou como honorário para a Itália. Essa ocupação, embora por curto período, revela o reconhecimento do governo italiano por seus préstimo e atitudes diplomáticas perante a colônia e cidadãos italianos junto às autoridades japonesas.

A nomeação de Wenceslau de Moraes como cônsul no Japão é consequência de uma guinada traumática de sua carreira e, por outro lado, a coroação de sua vida diplomática. É que, em 1895, por se sentir preterido na sucessão de cargos na Superintendência do Porto de Macau, Wenceslau abandonou tudo, sua casa, sua mulher e seus filhos, em Macau, e seguiu para se exilar voluntariamente em terras nipônicas que tanto lhe enchiam a alma e páginas de sua escrita.

\section{Considerações finais e conclusões}

Como vimos, a diplomacia no contexto do universo oriental aparece, por várias vezes, nas obras de Wenceslau de Moraes, e, especialmente, nas obras aqui analisadas, mais pontualmente Traços do Extremo Oriente e Paisagens da China e do Japão. As dificuldades diplomáticas do serviço exterior português também aparecem nas narrativas de Wenceslau de Moraes, onde, por exemplo, Macau é tratada ora como "o torrão português" no Extremo Oriente, ora como uma terra chinesa.

Desde seu primeiro livro, Traços do Extremo Oriente, o mundo oriental surge como um lugar explorado com grande 
curiosidade e prazer, ao início reportando didaticamente fatos demasiadamente exóticos ao olhar europeu. Com Paisagens da China e do Japão, a evolução da sua narrativa vai se complementando, compreendendo, orientalizando e se acostumando com aquele universo vis-à-vis um mundo europeu justaposto naquelas paragens. Contos, lendas, personagens e a própria vida do autor no Oriente constroem narrativas emocionantes para a compreensão do mundo asiático daquele período histórico.

A obra de Wenceslau de Moraes, além da beleza estética de sua narrativa, tem o condão de revelar ao mundo da língua portuguesa um universo oriental pitoresco que ali fica muito bem registrado como merecedor da compreensão e da efetivação de laços na construção de diplomáticas e amigáveis relações.

\section{Referências}

Fonseca, Edson Nery da. Nota do organizador. In: Freyre, Gilberto. China Tropical. Organizado por Edson Nery da Fonseca. Brasília: Editora da Universidade de Brasília; São Paulo: Imprensa Oficial, 2003.

Moraes, Wenceslau de. Paisagens da China e do Japão. Macau: COD, 2007. [1ª edição em 1906].

Moraes, Wenceslau de. Traços do Extremo Oriente. São Paulo: Sésamo, 2012. [1ª edição em 1895].

Antunes, Sérgio Pereira. Wenceslau de Moraes, suas obras e o serviço exterior português Na Ásia. In: Simas, Monica (Org.). Estudos sobre Macau e outros orientes. São Paulo: Paulistana, 2017. p. 111-127. 